\title{
editorial
}

\section{Dear Minister,}

I understand that times are tough for governments, no less than for individuals, trying to make ends meet in the face of the global recession. However, I am writing to appeal to you to take a bold step at this time, to secure our country's future.

As our traditional industries contract and manufacturing moves to those countries once considered under-developed, we need to replace the factory production line with our only viable commodity of the future, brainpower. Unless we can develop and market our expertize in cutting-edge technologies, the global recession will surely accelerate our relative decline.

We must create a ferment of marketable new ideas, and the only way to achieve that is by a major investment in science. Since researchers cannot be programmed to achieve a specific result, the best way to guarantee that they produce something tangible is to invest on an audaciously massive scale. A billion Euros spent on such an initiative is chicken-feed compared with the bail-outs that we have bestowed upon the banks. Make it three billion; why not 10 ?

Coupled with this new investment, resources need to be transferred from the fossilized parts of our academic system. Together with the new funding, they should be channelled into the creation of a network of prestige institutes that aim for nothing less than global pre-eminence. Although these should play to our national strengths, we need also to identify hot new areas with cross-disciplinary appeal. The topics need to be relevant to contemporary issues and problems, especially global ones, but at the same time their focus must be on pure not applied sciences. After all, pure research is where most applications actually arise.

Of course, if we develop a few top institutes at the expense of university education then we are just cutting our own throat in a different way. The new institutes need to be embedded within the universities, not established outside of them. They should integrate learning with a rigorous training in research. To bring this about you will need to create a new framework for university education that can by-pass or replace traditional faculties with structures that are geared to the top-level science that we seek to establish here.

We need to recruit the best researchers in the world and support them with the proper tools to develop their projects. We must structure our new institutes so as to attract clusters of scientists with overlapping interests, who can stimulate each other. We must also offer them substantially higher salaries than anything they can earn elsewhere, as well as an unrivalled starter package of funding that provides all the instrumentation, support staff and access to information that cutting-edge research requires.

We also need to pay great attention to the wider environment, not just the research infrastructure. We might, for example, have enticing sub-tropical beaches/snow-bedecked wildernesses/world-class opera/gastronomic elegance/sartorial chic but this is not enough. It is no good offering a top professor the earth if her husband can't find suitable employment or her kids can't get an education that is at least as good to anything they can get at home. If they have to sell their dream-house in California to move here, but then get locked into a property market that grows only half as fast as the one they have left, they will end up unable ever to move back: this distinctly unappealing prospect will deter them from coming in the first place. In short, you need to create a state agency dedicated to the inward relocation of top scientists that can find and implement creative solutions to such problems.

Assured institutional funding would mean that our new recruits will not need to waste too much time applying for external grants. However, if we appoint the right people they will compete successfully and with little effort for such grants, especially from international sources, thus creating a net inflow of funds. This argument might come in handy when you try to persuade your colleagues in the Ministry of Finance to support the plan.

In addition to recruiting from abroad, we must make our own graduates globally competitive, so as to create the workforce to sustain the world's best scientific institutes and industries. It should become the norm that we encourage our top graduates to pursue further training abroad, providing the necessary funding for them to secure places in the most prestigious institutions. Then we need to offer equally generous support to allow the brightest of them, who have succeeded at the postdoctoral level, to return home and establish their independent labs. By doing this, our new institutes will be continuously infused with fresh impetus and ideas.

All of this seems very ambitious and expensive, but I am sure you are well aware that it has been piloted with some degree of success already. Finland, which suffered a dramatic economic recession in the early 1990s when the Soviet Union collapsed, implemented exactly this type of policy to dig itself out of the hole. Strong investment in science and technology at that time helped to produce the so-called 'Nokia miracle'.

Despite all of the hardship it brings, the present recession creates a golden opportunity. People will accept the need for tough decisions, especially if they believe that such actions will bring future prosperity and will insulate us against the worst effects of the next crisis. The invisible benefits of creating a worldwide reputation for our country as a true pioneer of the technologies of the future surely outweigh all the costs.

If you find my proposal attractive, there is no time to lose. In fact, if we do not steal a competitive advantage now, we will face the strong risk of losing our best brains, enticed to relocate by exactly these opportunities offered elsewhere.

\section{Howy Jacobs}

doi:10.1038/embor.2009.110 